\title{
The role of antioxidant proteins in improvement of autism core symptoms in two patients with tuberous sclerosis treated with mTOR inhibitor everolimus
}

\author{
Kunio Yui ${ }^{1 *}$, Hitomi Sasaki ${ }^{1}$, George Imataka² and Toru Okanishi ${ }^{3}$ \\ ${ }^{1}$ Department of Urology, Fujita Health University School of Medicine, Aichi 470-1192, Japan \\ ${ }^{2}$ Department of Pediatrics, Dokkyo Medical University, Mibu 321-0293, Tochigi, Japan \\ ${ }^{3}$ Department of Neuropediatrics, Seirei Hamamatsu General Hospital, Hamamatsu, 430-8558, Sizuoka, Japan
}

\begin{abstract}
Background: The neuropsychiatric clinical manifestations of tuberous sclerosis complex (TSC) include social and behavioral impairment, which are similar to the core symptoms of autism spectrum disorder (ASD). The present study examined the clinical effects of the mTOR inhibitor everolimus for 24 weeks on social and behavioral symptoms, and its relation of serum levels of the copper- and iron-binding antioxidants, such as ceruloplasmin ( $\mathrm{Cp}$ ) and transferrin ( $\mathrm{Tf}$ ), and superoxide dismutase (SOD) in a pre-pubercent boy and a girl child with TSC.

Case presentation: MRI revealed a SEGA located at the foramen of Monro in the two patients and a renal angiomyolipoma (AML) on these patient's kidney in the one patient. Everolimus apparently improved the patients' social as well as behavioral impairments over the course of a $24-$ week treatment. Slight reductions in size of SEGA and AML in one patient, and slightly reduced SEGA in another patient. Serum Cp and Tf levels were gradually increased in response to the improvement of autistic symptoms.
\end{abstract}

Conclusion: Increased antioxidant activity may contribute to the improvement in the ASD social as well as behavioral symptoms with a $24-w e e k$ treatment of $t$ everolimus in two cases with TSC.

\section{Introduction}

Tuberous sclerosis (TSC) is a rare multi-system monogenic hamartomatous disorder that affects almost every organ in the body [1]. Patients with TSC have neurological deficits including seizures and behavioral and psychiatric deficits including autism spectrum disorder (ASD) with TSC-specific lesions such as subependymal giant cell astrocytomas (SEGA) and renal angiomyolipomas (AML) [2,3].

Clinical characteristics of ASD in young patients with TSC prented impaired social interaction including impairments of gestures, eye contact, responsive social affect, and shared enjoyment [4], and behavioral symptoms such as repetitive and stereotyped behavior $[5,6]$. These social and behavioral symptoms are completely similar to DSM5 criteria for the core social deficits and restricted, repetitive patterns of behavior [7]. Approximately $60 \%$ of patients with TSC are diagnosed with ASD [8].

Tuberous sclerosis complex 1 and tuberous sclerosis complex 2 are the tumor-suppressor genes and inactivating mutation in one of these genes may be resulted in hyperactivity of the manmalian target of rapamycin (mTOR), inducing the tumorous symptoms in TSC [811]. Results from both human and animal studies have suggested that mTOR inhibitors improve deficits in social interaction and abnormal autistic behavior in human [5,6] and in TSC mouse models [12]. However, there are a few studies of the clinical effect of the mTOR inhibitor everolimus on ASD symptoms. A previous review articles suggested that mutation of TSC 1 and TSC2 were characterized by hyperactivity of mTOR, but the contribution of this mechanism to development of ASD still unclear [13,14]. Moreover, according to a previous review article, animal models with heterozygous mutations in Tsc1 or Tsc2 exhibited ASD-like social deficit in the absence of cortical lesion [14]. Thus, other neurobiological mechanisms may contribute to the development of ASD symptoms in TSC. Thus, Importantly, the mTOR pathway is closely related oxidative stress [15] or antioxidant capacity [16]. Oxidative stress-induced reactive oxygen species [17] enhanced mTOR [15]. Particularly, copper-related antioxidants, such as ceruloplasmin (Cp) [18] and iron-related transferrin (Tf) [19] are closely related to mTOR signaling. For example, Cp expression may be related to activation of mTOR pathway [18]. Tf uptake modulates the mTOR signaling pathway [20]. Thus, the ASD symptoms may depend on other neurobiological mechanisms.

This study attempted to examine the possibility that everolimus treatment may improve the ASD symptoms in relation to increased serum levels of Cp and Tf levels in two cases with TSC

Correspondence to: Kunio Yui MD PhD, Visiting Professor, Department of Urology, Fujita Health University, Toyoake, Aichi, Japan, Tel: 8178791 8981; Fax: 8179237 8755; E-mail: yui16@bell.ocn.ne.jp

Key words: Tuberous sclerosis, mTOR inhibitor, everolimus, autism spectrum disorder, ceruloplasmin, transferrin

Received: February 02, 2018; Accepted: February 12, 2018; Published: February 15,2018 
Yui K (2018) The role of antioxidant proteins in improvement of autism core symptoms in two patients with tuberous sclerosis treated with mTOR inhibitor everolimus

\section{Case presentation}

\section{Case 1 (patient A)}

Subject characteristics: The patient A was 11 years old male patient with TSC accompanied with the core ASD symptoms. He was born at 37 weeks of gestation by normal delivery with $2,856 \mathrm{~g}$. At the age of 13 months, the patient experienced first episode of typical infantile spasms, which is an age-related epileptic encephalopathy, and catastrophic status [21], consisting of a sudden extension of the axis and proximal limb musculature with a duration of 30 minutes, and the patient was treated with predonine and benzodiazepine for four months. From the age of 17 months, the patient was treated with various types of antiepileptics, including sodium valproate and carbamazepine until 12 years of age, and his epileptic seizure never recurred.

\section{MRI findings}

At the age of 8 years, brain magnetic resonance imaging (MRI) showed a subependymal giant cell astrocytoma (SEGA) $(2.1 \mathrm{~cm} \mathrm{x}$ $4.0 \mathrm{~cm}$ ) located at the right foramen of Monro within a coronal T2weighted image (Figure 1a, white arrow). At the age of 9 years old, he received keyhole craniotomy for this SEGA. Eight months after his keyhole operation (at the age of 10 years), MRI revealed small SEGA $(0.5 \times 0.4 \mathrm{~cm})$ on the left foramen of Monro (Figure 1b, white arrow), and two small renal angiomyolipomas (AML) (both were $0.8 \mathrm{~cm} \mathrm{X} 0.8$ $\mathrm{cm}$ ) (Figure 1c) on the patient's left kidney and multiple renal cystes on the right kidney (Figure 1c, small white arrows). These MRI findings including two major diagnostic criteria such as a SEGA and a AML met the diagnostic criteria for TSC [22] without genomic analysis.

\section{ASD symptoms}

The patient never exhibited any deficits in social interaction and repetitive behaviors until 5 years of age. From 6 to 10 years of age, the patient's impaired social interaction gradually developed. However, the patient did not receive any psychosocial or psychotherapeutic treatment because the attending pediatrician's doctors recognized his social and communication deficits as organic TSC-related secondary symptoms.

The patient never responds to many forms of non-verbal communication, including facial expressions and engage in eye contact with his family members and others because he was unable to understand their needs. He often showed delayed speech and sometimes created neologisms and idiosyncratic language. His speech was confined to narrow topics of expertise. Thus, he gradually withdrew into his repetitive play and behavior. He exhibited delayed acquisition of motor skills, and had difficulty with motor coordination, postural control, and imitating the movements of other people. He had a consistent habit of washing his face in the morning and maintained this habit. When his routine was changed, he usually entered a state of panic. Because of his severe impairment in reciprocal social interaction, he was moved from a normal school to a special needs school at the age of 10 years.

\section{Diagnosis of ASD}

At the age of 11 years, the patient A participated in our clinical trial at the Department of Pediatrics at Dokkyo Medical University, Japan. Diagnostic evaluation was conducted using the Autism Diagnostic Interview-revised (ADI-R) and Autism Diagnostic Interview Schedule (ADOS). This assessment was performed by two psychiatrists who specialize in ASD. The ADI-R is a standardized, semi-structured, investigator-based interview for parents or caregivers of individuals with ASD [23]. The ADI-R was used to diagnose ASD in many individuals aged 4 and 18 years of age [24]. The ADOS was a semistructured, standardized assessment designed for use in the diagnostic evaluation of individuals with suspected autism spectrum disorder (ASD) [25]. His ADI-R scores were above the diagnostic cutoff scores for reciprocal interaction (his score was 18 , cutoff $=10$ ), the verbal (his score was 14 ; cutoff $=8$ ) and non-verbal communication (his score was 10 ; cutoff $=7$ ) and stereotyped behavior (his score was 4 ; cutoff $=13)$. The patient's total score on ADOS module 2 algorithm showed 17.0, which was greater than the total scores of the ADOS $(8.94 \pm 9.71)$ recently reported in 33 adolescents with high-functioning autism [26]. These findings indicated a definite ASD diagnosis. These findings indicating a ASD diagnosis.

\section{Intelligence test}

At the age of 10 years, he received intelligent test using the Wechsler Intelligence Scale for Children [27]. His total Intelligence Quotient (IQ) was 67, which was defined as borderline IQ [28].

\section{Assessment of ASD symptoms}

The patient's ASD severity was assessed using the ADOS. Social impairment was assessed using the Social Communication Questionnaire (SCQ) and Social Responsiveness Scale (SRS) [29]. The SCQ is a measure for parents/caregivers to assess their child's reciprocal social interaction, communication, and repetitive, stereotyped domains [30] based on the ADI-R. The SRS is highly feasible for the quantitative ascertainment of autistic social impairment [31]. Behavioral symptoms
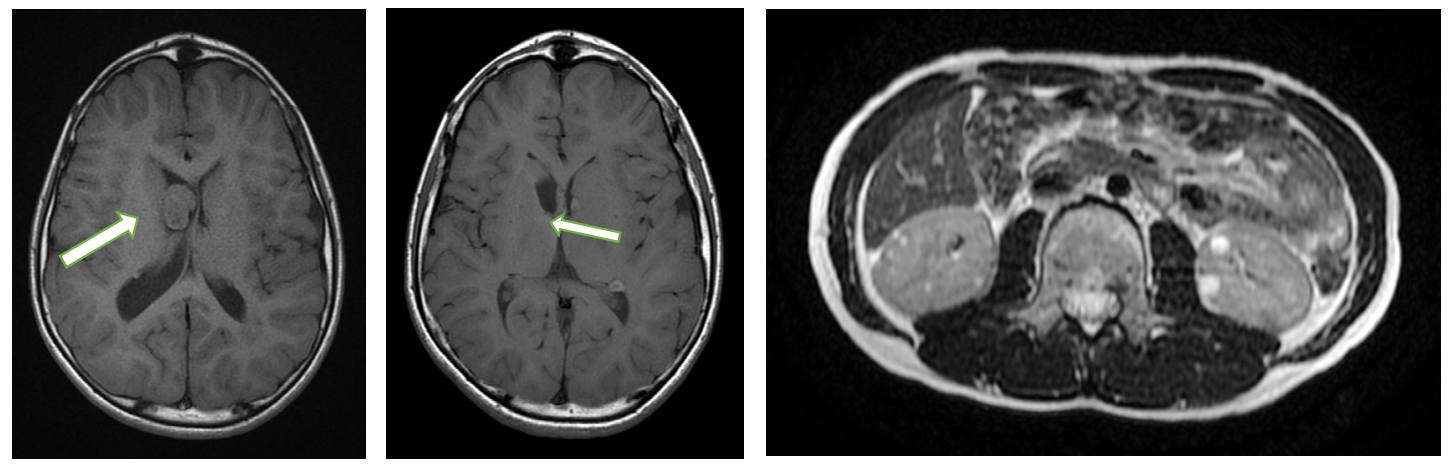

Figure 1. Brain and kidney MRI findings of the patient A. a MRI revealed a subpendeymal giant cell astrocytoma (SEGA) located at the right foramen of Monro (white arrow); b Brain MRI after keyhole operation, most of the SAGE was removed. At the 10 years old, small SEGA $(0.5 \times 0.4 \mathrm{~cm})$ was detected at the left foramen of Monro after two years and eight months (white arrow); c MRI showed left two low-density areas with negative Hounsfield unit values inside the kidney, suggesting a renal angiomyolipoma (AML) (white arrows) and four multiple renal cystes (small arrows). 
Yui K (2018) The role of antioxidant proteins in improvement of autism core symptoms in two patients with tuberous sclerosis treated with mTOR inhibitor everolimus

were assessed using the Aberrant Behavior Checklist (ABC). The ABC is intended to evaluate treatment responses in psychopharmacological and behavioral intervention trials for children and adolescents with mental retardation [32] and normal IQ levels [33]. As shown in figure 2, the patient's total score on the ADOS was greater than the total score in 33 adolescents with high-functioning autism [25]. The patient A's SRS and ABC total scores were 125 and 113, respectively. These SRS and $\mathrm{ABC}$ scores were greater than those of ASD individuals with an age range of 13-27 years (SRS, 120.12; ABC, 60.14) [34]. The SCQ cutoff score was compared with established cutoffs for ASD screening (scores 215) [35] mal range (cut-off score $\geq 15$ ).

Collectively, his social and behavioral symptoms were within at least the moderate-severe range. Other evaluations, including an ophthalmologic and dental examinations at the pretreatment and posttreatment screenings revealed no abnormalities.

\section{Biochemical measurement}

mTOR inhibition and vascular endothelial growth factor-D (VEGF) expression were closely associated with synergistic antitumor activity [36]. Serum VEGF-D was used as a useful biomarker for monitoring treatment responses to the mTOR inhibitor sirolimus [37].

Moreover, the mTOR is closely associated with antioxidant capacity $[16,19,20,38,39]$, serum levels of antioxidant proteins such as ceruloplasmin $(\mathrm{Cp})$, transferrin $(\mathrm{Tf})$ and superoxide dismutase (SOD) were measured by the SRL. Ltd. (Tokyo, Japan).

\section{Serum assay for serum VEGF-D}

Blood samples were centrifuged at $1400 \times g$ for $10 \mathrm{~min}$ within $30 \mathrm{~min}$ of collection. The samples were stored at $-80^{\circ} \mathrm{C}$ until assay by ELISA (the Quantikine Human VEGF kit). The limits of sensitivity of the ELISA are $31.2-2,000 \mathrm{pg} / \mathrm{ml}$ and sensitivity were $5 \mathrm{pg} / \mathrm{ml}$ (Funakoshi, Co., Ltd) [40]. All of the samples were measured in duplicate.

\section{Serum assay for everolimus}

Serum everolimus levels were determined after liquid extraction by a liquid chromatography-mass spectroscopy method with lower limits of quantification for everolimus of $0.3 \mathrm{ng} / \mathrm{mL}$ [41].

\section{Serum assay for ceruloplasmin, transferrin and superoxide dismutase}

Whole-blood samples were collected in EDTA tubes by venipuncture and immediately placed on ice in a refrigerator. The specialists at SRL, Inc (Tokyo, Japan) measured the plasma levels of PUFAs, $\mathrm{Cp}$, Tf and SOD. Seum Cp levels were measured using a Bering BN 『Nephelometer (Siemens Healthcare Diagnostics K.K., USA) [42].
Serum levels of SOD were assayed using an SOD Assay Kit (Takara Bio, Tokyo) according to the cytochrome c method [43]. Serum Tf levels were estimated using a standard turbidimetric assay and an automated biochemical analyzer (JCA-BM8000 series, JEOL Ltd., Tokyo, Japan) [44].

\section{Results of these assays}

Serum levels of VEGF were $252.6 \mathrm{pg} / \mathrm{ml}$ at baseline and gradually increased to peak values $(315.1 \mathrm{pg} / \mathrm{ml})$ at 12 weeks and then gradually decreased from $16(289.5 \mathrm{pg} / \mathrm{ml})$ to 24 weeks $(247.4 \mathrm{pg} / \mathrm{ml})$ after treatment. Serum everolimus levels were $9.58 \mathrm{ng} / \mathrm{ml}$ at 12 weeks, increased to $18.1 \mathrm{ng} / \mathrm{ml}$ at 16 weeks, and then decreased to $7.32 \mathrm{ng} / \mathrm{ml}$ at 24 weeks after treatment.

Importantly, serum Cp levels gradually increased from baseline $(19 \mathrm{mg} / \mathrm{dl})$ to 16 weeks $(32 \mathrm{mg} / \mathrm{dl})$ and then remained higher than the baseline levels (Figure 3, upper panel). Serum Tf levels were gradually increased from baseline $(282 \mathrm{mg} / \mathrm{dl})$ to peak values at 16 weeks (386 $\mathrm{mg} / \mathrm{dl})$, and then gradually decreased at 24 weeks $(288 \mathrm{mg} / \mathrm{dl})$, in accordance with symptom improvement (Figure 3, upper panel). While, serum SOD levels were slightly increased at 8 weeks of treatment, and then slightly decreased at 16 weeks, suggesting less contribution to the efficacy of everolimus (Figure 3, upper panel).

\section{Treatment}

\section{Keyhole Surgery in SEGA}

At the age of 10 years old, he received keyhole craniotomy for SEGA. "keyhole" method is conducted in the case of sufficient for exposing large areas deep in tissue, enabling adequate removal and decompression [45]. After this operation, although ASD symptoms were not improved, progressive augmentation of the ASD symptoms was not detected.

\section{Treatment with everolimus and serum everolimus levels}

The patient A was treated with $4.4 \mathrm{mg} /$ day of everolimus for 24 weeks. The patient A's body surface area was $1.47 \mathrm{~m}^{2}$, and thus the median maintenance dosage of everolimus was $4.4 \mathrm{mg} / \mathrm{m}^{2} /$ day based on $3 \mathrm{mg} / \mathrm{m}^{2}$ in the Novartis indication. Serum levels during the maintenance dose were $9.58 \mathrm{ng} / \mathrm{ml}$ at 12 weeks, $18.1 \mathrm{ng} / \mathrm{ml}$ at 16 weeks, $15.1 \mathrm{ng} / \mathrm{ml}$ at 20 weeks, and $7.3 \mathrm{ng} / \mathrm{ml}$ at 24 weeks after the treatment. Ointment was applied because of a slight degree of inflammation of his oral mucosa as a common side effect of everolimus, however, no severe or life-threatening side effects related to everolimus treatment were observed. Everolimus induced remarkable improvement in the social and behavioral symptoms without dose adjustment during the treatment.
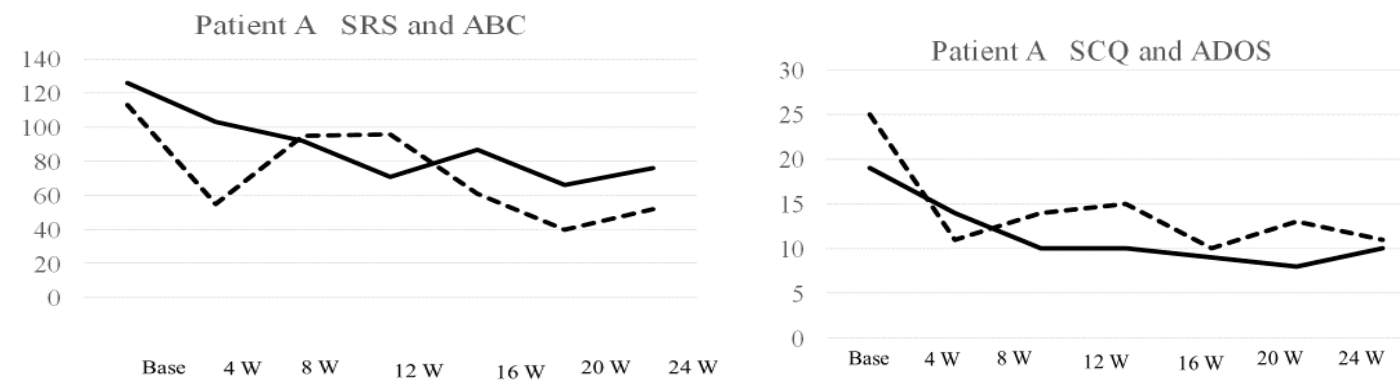

Figure 2. Brain and kidney MRI findings of the patient B. a MRI revealed a subpendeymal giant cell astrocytoma (SEGA) located at the right foramen of Monro (white arrow); b Brain MRI revealed four subpendeymal nodules (white arrow). 


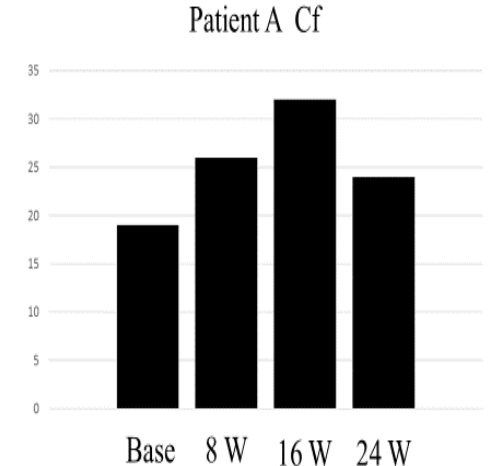

Base $8 \mathrm{~W} \quad 16 \mathrm{~W} 24 \mathrm{~W}$

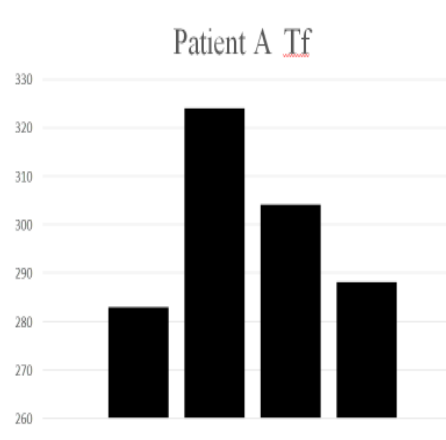

Base $8 \mathrm{~W} \quad 16 \mathrm{~W} \quad 24 \mathrm{~W}$

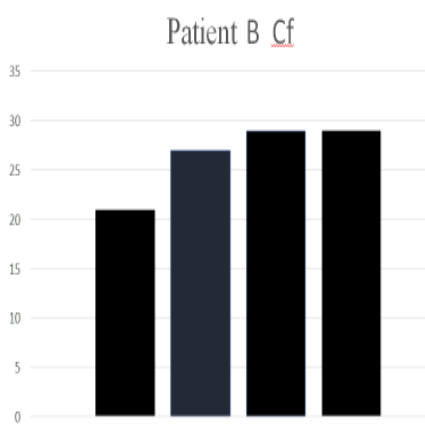

Base $8 \mathrm{~W} \quad 16 \mathrm{~W} \quad 24 \mathrm{~W}$

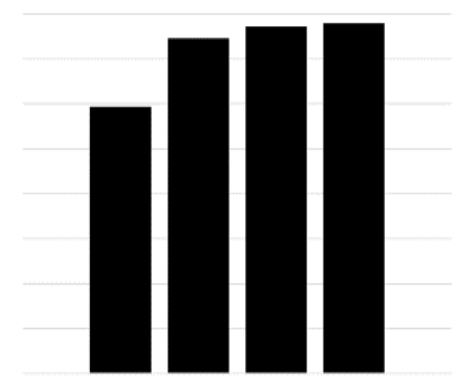

Base $8 \mathrm{~W} \quad 16 \mathrm{~W} 24 \mathrm{~W}$

Figure 3. Total scores of Social Responsiveness Scale (SRS), Aberrant Behavior Checklist (ABC), Social Responsiveness Scale (SRQ) and Autism Diagnostic Observation Schedule (ADOS) in patient A.

\section{Clinical symptoms after everolimus treatment}

Everolimus treatment induced aooarent improvement in impaired social cognition, social interaction, and mutual communication. Three months after the treatment, the patient $\mathrm{A}$ was able to understand and follow some verbal commands issued by his mother and classmates, and frequently communicated with his family members and classmates. After four months, repetitive motions, such as swaying, or twirling disappeared. He also had less trouble understanding other people's feelings.

The patient A's SRS, ABC, SCQ and ADOS total scores were gradually decreased, indicating a decrease in the social and behavioral consequences of ASD symptoms. Interestingly, the SRS and ABC total scores decreased from 126 before treatment to 76 (40\% decrease), and from 113 before treatment to 54 following treatment (54\% decrease), respectively compared with baseline. Thus, everolimus treatment remarkably improved the patient's social as well as behavioral symptoms.

There was slight size reduction $(0.3 \mathrm{~cm})$ of the patient's SEGA on the right foramen of Monro after the 24-week treatment (Figure 2b). The sizes of two AML were slightly reduced $(0.4 \mathrm{~cm})$ after 24 weeks of treatment.

\section{Case 2 (patient B) \\ Patient Characteristics}

The second patient (Patient B) was a 6-year-old girl with TSC accompanied by the core ASD symptoms and seizures. She was born by spontaneous vaginal delivery and had a birth weight of $2060 \mathrm{~g}$. She received phototherapy because of neonatal jaundice at the time of birth. At the age of 6 months, she exhibited infantile spasms associated with age-related epileptic encephalopathy and developed a catastrophic status [21] consisting of sudden extension of the axis and proximal limb musculature for a duration of 2 to 3 minutes. At the age of 13 months, she experienced her first episode of complex partial seizures, which are a presenting sign in many young children with TSC [1]. Her seizures consisted of sudden loss of consciousness for 2 minutes and occurred several times a week. The patient was treated with different types of anticonvulsants, such as sodium valproate and carbamazepine. Her epilepsy gradually increased in frequency and severity, with a poor response to the antiepileptic drugs. Her electroencephalogram frequently showed spikes and spike-and-wave complexes at the central areas $(\mathrm{Cz}$ and $\mathrm{C} 3)$, which are sometimes recognized in patients with complex partial seizures [46].

\section{MRI findings}

At the age of 6 months, MRI revealed SEGA $(0.5 \times 0.5 \mathrm{~cm})$ located at the right foramen of Monro within a coronal T2-weighted image (Figure 4, white arrow), and subpendymal nodules located at beside interventricular form. There was no AML in her kidney. These MRI findings including two major diagnostic criteria such as a SEGA and subpendymal nodules met the diagnostic criteria for TSC [22]. Thus, the diagnosis was confirmed without genomic analysis.

\section{Autism spectrum disorder symptoms}

From the age of 7 months, the patient B gradually developed impairment of social interaction. She did not respond to many forms 
Yui K (2018) The role of antioxidant proteins in improvement of autism core symptoms in two patients with tuberous sclerosis treated with mTOR inhibitor everolimus
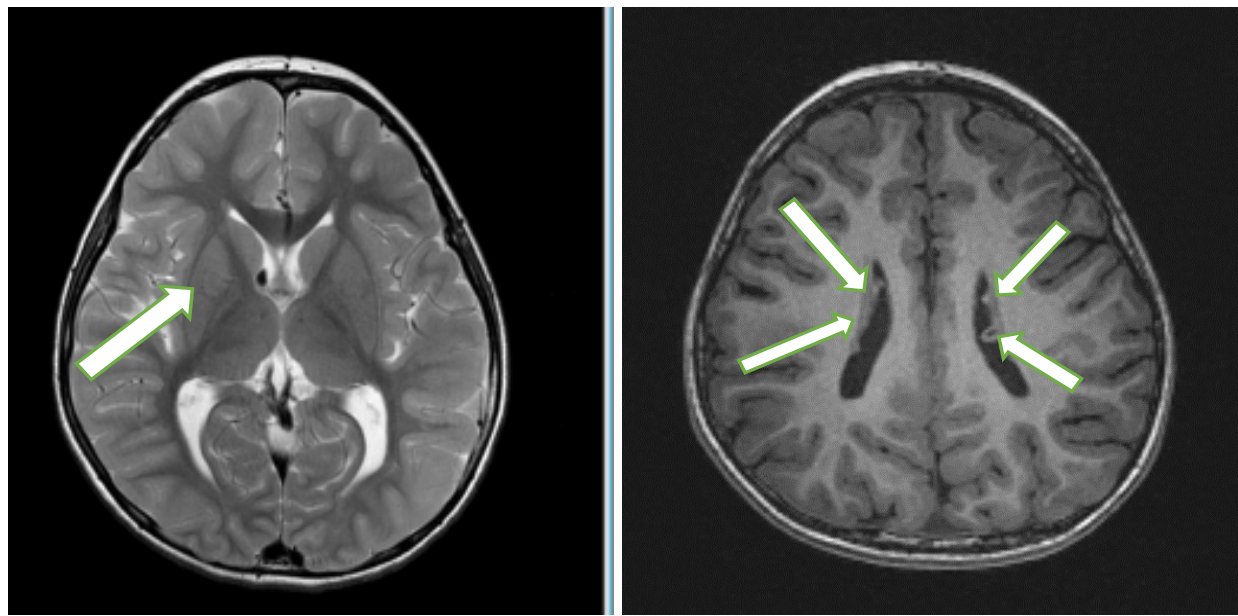

Figure 4. Total scores of Social Responsiveness Scale (SRS), Aberrant Behavior Checklist (ABC), Social Responsiveness Scale (SRQ) and Autism Diagnostic Observatiob Schedulen (ADOS) in patient B.

of nonverbal communication by facial expressions, physical gestures, or eye contact. She was unable to interpret and understand the interests and needs of other children. She often engaged in "parallel play" at the edge of a group rather than joining in cooperative play and did not engage in pretend play. She exhibited delayed speech and struggled to make sense of nonverbal forms of communication. She found it difficult to form and sustain friendships with other children because of her difficulties with social and emotional responsiveness. She was very sensitive to the sound of fireworks and starting pistols. Although she desired to form friendships with other children, she exhibited inappropriate friendliness and lack of awareness of others' interests and needs because she was unable to understand their needs. Thus, she worked upon other children regardless of their dislike. She also sometimes created fictional tales by talking to herself in a loud voice in her home and in kindergarten during lectures. The patient wanted to spend time playing by herself at the edge of a group. She was often unable to understand what her teachers and classmates said, and her teachers sometimes provided guidance to help her understand.

With respect to behavioral symptoms, the patient B usually was not able to engage in group games, imitate others, collaborate, or use their toys in creative ways. Her play also tended to have a persistent sensorimotor or ritualistic quality. Her behaviors were characterized by repetitive and stereotyped patterns of activities such as repetitive drawing of faces of children for approximately 30 minutes. She exhibited delayed acquisition of motor skills and had difficulty with motor coordination, postural control, and imitating the movements of other people. She was unable to run along lines and was very sensitive to starting pistols in sport meetings.

\section{Psychometric evaluation}

At age 5 years, the patient B participated in our clinical trial at the Department of Pediatrics at Seirei Hammatsu General Hospital in Japan and she took psychometric tests. Her ADI-R scores were above the autism diagnostic cutoff scores for qualitative abnormalities in reciprocal interaction (her score was 13 , cutoff $=10$ ), qualitative abnormalities in communication for both the verbal (her score was 14; cutoff $=8$ ) and non-verbal total scores (her score was 9; cutoff $=7$ ), and repetitive/stereotyped patterns of behavior was low the cut-off score (her score was 4 ; cutoff $=3$ ). These ADI-R scores indicated confirm a diagnosis of ASD.
As shown in figure 5 , the patient B's total score on the ADOS module 2 algorithm showed a communication score of 10.0 , which was greater than the total scores of the ADOS $(8.94 \pm 9.71)$ reported in 33 adolescents with high-functioning autism [25]. Her SRS and ABC total scores were 80 and 36 , respectively. The total SRS and ABC scores were lower than those of ASD individuals with an age range of 13-27 years (SRS, 120.12; ABC, 60.14) [34]. The patient B's social and behavioral ASD symptoms appeared to be less severe. As the SCQ cutoff score was compared with established cutoffs for ASD screening (scores of $\geq 15$ ) [35], the patient B's SCQ score of 10 was within the normal range. At the age 6 years she received intelligent test using the WISC for Children [27]. Her total Intelligence Quotient was 61, which was defined as borderline IQ [28].

Collectively, her social and behavioral symptoms were within the moderate range of ASD symptoms. Other evaluations revealed no additional abnormalities.

\section{Biochemical measurement}

The patient B's serum level of VEGF-D was $336.9 \mathrm{pg} / \mathrm{ml}$ at baseline and $548.7 \mathrm{ng} / \mathrm{ml}$ at week 8 , and gradually increased to peak values of value of $571.4 \mathrm{pg} / \mathrm{ml}$ at 16 weeks, then decreased to $501.5 \mathrm{pg} / \mathrm{ml}$ at 24 weeks after treatment. Thus, the peak serum VEGF level was higher inpatient $B$ than in patient $A$.

As shown in figure 4, serum Cp levels gradually increased from baseline $(20 \mathrm{mg} / \mathrm{dl})$ to 16 weeks $(29 \mathrm{mg} / \mathrm{dl})$ and then remained higher than the baseline levels at 24 weeks $(29 \mathrm{mg} / \mathrm{dl}$ ) (Figure 5 lower panel). Serum Tf levels were gradually increased from baseline $(297 \mathrm{mg} / \mathrm{dl})$ to peak value at 24 weeks $(390 \mathrm{mg} / \mathrm{dl})$ in accordance with symptom improvement (Figure 3, lower panel). Thus, it is important to note that serum $\mathrm{Cp}$ and $\mathrm{Tf}$ levels were gradually increased 16-24 weeks of treatment, in accordance with symptom improvement in the patient B. While, serum SOD levels tended to decrease from the baseline ( $4.7 \mathrm{pg} /$ $\mathrm{ml}$ ) to 24 weeks of treatment, suggesting no contribution to the efficacy of everolimus (Figure 3, lower panel).

\section{Treatment with everolimus and serum everolimus levels}

After the physical screening, patient B received $1.9 \mathrm{mg}$ of everolimus every day for 24 weeks. The patient's body surface area was $0.63 \mathrm{~m}^{2}$, based on $3 \mathrm{mg} / \mathrm{m}^{2}$ in the Novartis indication. The serum everolimus levels during maintenance dosing were 7.0, 7.5, and $7.9 \mathrm{ng} /$ 
Yui K (2018) The role of antioxidant proteins in improvement of autism core symptoms in two patients with tuberous sclerosis treated with mTOR inhibitor everolimus

Patient $\mathrm{B}$ SRS and $\mathrm{ABC}$

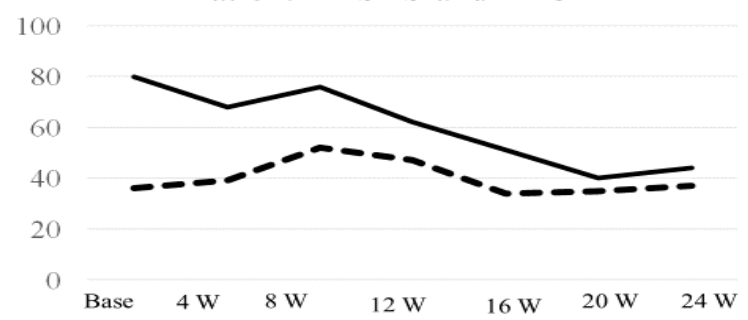

Patient B SCQ and ADOS

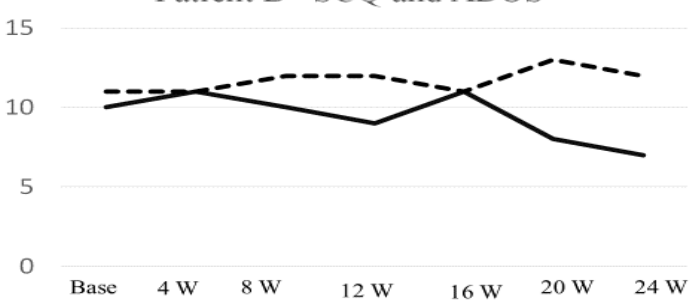

Figure 5. Serum levels of ceruloplasmin (Cp), transferrin (Tf) during the treatment with everolimus for 24 weeks in patient A and patient B.

$\mathrm{ml}$ at 12,16 , and 24 weeks after treatment, respectively. One week after the everolimus treatment, she suffered from mild lung inflammation, but she immediately recovered by steroid treatment. She was also treated with topical ointment because of slight inflammation of her oral mucosa, which is a common side effect of everolimus. However, no severe or life-threatening side effects related to everolimus treatment were observed.

\section{Clinical symptoms after everolimus treatment}

The everolimus treatment induced apparent improvements in her social interactions and verbal and nonverbal communication skills. She showed gradual language development without a dose adjustment during the 24 weeks of treatment. She was able to appropriately communicate with classmates and adults and showed pretend play skills. Thus, she was gradually able to enjoy school life.

The patient B's SRS and SQC scores gradually decreased, indicating improvement of the social impairment. In particular, the SRS and SCQ total scores decreased from 80 before treatment to 44 following treatment (decrease of $45 \%$ ), and from 19 before treatment to 10 following treatment ( $47 \%$ decrease), respectively compared with baseline. Thus, the everolimus treatment induced remarkable improvements in the patient B's social impairment. While, the ABC total score was not changed.

The size of the SEGA was also slightly reduced $(-0.2 \mathrm{~cm})$, and that of subpendymal nodules were not changed after the everolimus treatment.

\section{Discussion}

This study presented for the first time that everolimus treatment for 24 weeks apparently improved the core social as well as behavioral symptoms of ASD in two patients. The core ASD symptoms appeared with a SEGA and AML in Patient A, and with SEGA and subpendymal nodules in Patient B. These findings indicate that the core ASD symptoms may be related to the presence of a SEGA. Importantly, the present findings indicate that the increased serum Cp and Tf levels may have contributed to the improvements in the core ASD symptoms.

In patient $\mathrm{A}$, the serum everolimus levels were 18.10 and $7.32 \mathrm{ng} /$ $\mathrm{ml}$ at 16 and 24 weeks after treatment, respectively. In patient B, the serum everolimus levels were 7.0 and $7.9 \mathrm{ng} / \mathrm{ml}$ at 16 and 24 weeks after treatment, respectively. A previous study of the pharmacokinetics of everolimus revealed a mean everolimus blood level of $10.1 \pm 0.7 \mathrm{ng} /$ $\mathrm{ml}$ at 20 weeks after treatment in 25 healthy adolescents [41]. This level is similar to those in-patient $A$, indicating adequate levels of everolimus. With respect to the patient $\mathrm{B}$, considering that maintaining the everolimus trough in the range of 3 to $8 \mathrm{ng} / \mathrm{ml}$ was associated with good efficacy and safety profiles [47], the serum everolimus levels (7.0$7.9 \mathrm{mg} / \mathrm{ml}$ ) may be appropriate for improvement of social impairment.
The SRS total scores decreased by 40 to $45 \%$ in these two patients. As a $50 \%$ reduction in the initial states was considered as achieving a clinically significant improvement [48], everolimus treatment showed a trend toward significantly improved the patient's ASDl symptoms. Thus, proper treatment with everolimus may exert a life-enhancing clinical effect on the core social as well as behavioral symptoms. Similarly, a previous study showed that everolimus treatment improved social interaction; cognition; attention; behavioral deficits such as swaying, twirling, and preoccupation with flowing water; and seizures [49]. This finding may support our present case study.

In this study, the serum VEGF-D levels gradually increased from baseline $(252.6 \mathrm{pg} / \mathrm{ml})$ to a peak value of $315.1 \mathrm{pg} / \mathrm{ml}$ at 12 weeks in the patient $\mathrm{A}$, and serum VEGF levels gradually increased from baseline $(426.7 \mathrm{pg} / \mathrm{ml})$ to a peak value $(571.4 \mathrm{pg} / \mathrm{ml})$ at 16 weeks in the patient B (Figure 4). A previous study reported that the average serum level of VEGF in 19 normal healthy children was $306.1 \pm 39.4 \mathrm{pg} / \mathrm{ml}$ [50]. Although the patient B's serum VEGF-D levels at baseline were higher than the range reported in normal children, the serum VEGF-D levels gradually increased between 8 and 16 weeks. Considering that the serum VEGF-D levels are considered a biomarker of the treatment response [51], gradually increases in the serum VEGF-D levels observed in the patient $\mathrm{B}$ and the patient $\mathrm{A}$ indicate the response to everolimus.

The reduction in SEGA size was associated with a decrease in seizure frequency with everolimus treatment in in 28 children aged 3 years or older [2] and in 3-year-old children [52]. The effects of a reduction in the AML size on clinical symptoms was not reported [53]. The patient A's slight reduction in AML (-14.3\%) may be no apparent relationship with the symptom improvement. Although many studies found a $50 \%$ reduction in the SEGA, several studies reported slight decrease in SEGA size after everolimus treatment [14,54]. As the variable effects of everolimus on reduction of SEGA size reported in these previous studies, small size reduction observed in the two cases may be reasonable. Considering that the therapeutic benefit of everolimus may prevent the development of SEGA and AML [53,55], the ASD may depend on other neurobiological mechanisms of everolimus.

Importantly, many previous studies indicated an increase in antiocVEGF as exogene oxidant capacity. For example, VEGF-D deficiency may induce oxidative stress [56]. Moreover, exogenous stimulation of incVEGF-D cells induces an antioxidant response in human endothelial cells [57]. Everolimus attenuates oxidative stress by altering antioxidant levels [16] (Das) or reversing the accumulation of oxidative stress-related reactive oxygen species [58] (Dermit). Thus, elevated VEGF-D levels may be related to enhanced antioxidant capacity. It is important to note that everolimus attenuates oxidative stress by altering antioxidant levels [16] or reversing the accumulation 
Yui K (2018) The role of antioxidant proteins in improvement of autism core symptoms in two patients with tuberous sclerosis treated with mTOR inhibitor everolimus

of oxidative stress-related reactive oxygen species [58]. Everolimus may therefore increase antioxidant capacity. Everolimus treatment elevated serum VEGF-D levels in this study, increasing antioxidant capacity. Collectively, the everolimus treatment increase may be related to an increase serum antioxidant levels such as increased serum $\mathrm{Cp}$ and $\mathrm{Tf}$ levels. Of reference, $\mathrm{Cp}$ is the main copper-binding protein in blood plasma [59] and an important serum antioxidant [60]. Increased intracellular copper levels suppressed mTOR signaling [61] and copper treatment downregulated mTOR signaling [62]. With respect to increased serum Tf levels, the mTOR signaling pathway modulates Tf uptake [20], and mTOR regulates iron homeostasis through the Tf receptor [19]. Additionally, the Tf receptor may be useful for measuring intracellular changes in mTOR activity [63]. Taken together, everolimus may increase the antioxidant capacity as shown by the increased serum $\mathrm{Cp}$ and Tf levels. With respect to the association between $\mathrm{Cp}$ and $\mathrm{Tf}$, the transfer of iron was regulated by both $\mathrm{CP}$ and $\mathrm{Tf}$ and that the activity of $\mathrm{Cp}$ was modulated by $\mathrm{Tf}$ [64]. Cp plays an important role in iron metabolism [65]. Those previous data support the present finding that everolimus might act on mTOR signaling by increasing the serum $\mathrm{Cp}$ and $\mathrm{Tf}$ levels. The main role of SOD is to prevent the formation of aggressive reactive oxygen species [60], which were induced by excess oxidative stress [66], suggesting less contribution of the serum SOD levels to the efficacy of everolimus.

\section{Conclusion}

The present study first revealed that a 24 -week everolimus treatment increased activity of antioxidant such as $\mathrm{Cp}$ and $\mathrm{Tf}$, and thus may contribute to the apparent improvement in the social as well as behavioral ASD symptoms in the prepubercent boy and a girl child with TSC

\section{Contribution of authors}

All authors met the criteria for this journal's authorship credit in the author guide

Each author's name next to the appropriate category.

Study conception and design: Kunio Yui

Acquisition of data: George Imataka, Touru Okanishi and Kunio Yui

Analysis and interpretation of data: George mataka, Touru Okanishi and Kunio Yui

\section{Drafting of manuscript: Kunio Yui, Hitomi Sasaki}

Critical revision: Hitomi Sasaki, George Imataka

\section{Funding source}

This study was supported by a small research grant such as Grantin-Aid for Scientific Research (C) (2014-2016) from the Ministry of Education, Culture, Sports, Science and Technology, Japan.

\section{Conflict of interest}

The authors are not currently applying for any patents relating to the content of the manuscript, and did not receive reimbursements, fees, funding, or salary from an organization that holds or has applied for patents relating to the content of the manuscript. The authors declare that they have no conflict of financial and non-financial interest.

\section{Acknowledgements}

The authors thank patients' mothers for providing each patient medical information

\section{Ethical statements}

All the procedures in this study were in accordance with the ethical standards of Dokkyo Medical University, Tochigi, Japan (NO. 27014, Japanese Medical Association, Clinical Trial Registration (JMASIIA00258), and with the 1964 Declaration of Helsinki. All procedures were performed at the Department of Psychiatry, Dokkyo Medical University. Written informed consent was obtained from the patient's mother because the patient was unable to understand informed consent. Because the patient was minor child, the patient's mother provided her written consent for the publication of this case report on the behalf of the patient.

\section{References}

1. Curatolo P, Moavero R, De Vries JP (2015) Neurological and neuropsychiatric aspects of tuberous sclerosis complex. Lancet Neurol 14: 733-745. [Crossref]

2. Krueger DA1, Care MM, Holland K, Agricola K, Tudor C et al. (2010) Everolimus for subependymal giant-cell astrocytomas in tuberous sclerosis. $N$ Engl J Med 363: 1801-1811. [Crossref]

3. Kothare SV1, Singh K, Hochman T, Chalifoux JR, Staley BA et al. (2014) Genotype phenotype in tuberous sclerosis complex: associations with clinical and radiologic manifestations. Epilepsia 55: 1020-1024. [Crossref]

4. Jeste SS, Varcin KJ, Hellemann GS, Gulsrud AC, Bhatt R et al. (2016) Symptom profiles of autism spectrum disorder in tuberous sclerosis complex. Neurology 87: 766772. [Crossref]

5. Ehninger D1, Silva AJ (2011) Rapamycin for treating Tuberous sclerosis and Autism spectrum disorders. Trends Mol Med 17: 78-87. [Crossref]

6. Kilincaslan A, Kok BE, Tekturk P, Yalcinkaya C, Ozkara C et al. (2017) Beneficial effects of everolimus on autism and attention-deficit/hyperactivity disorder symptoms in a group of patients with tuberous sclerosis complex. J Child Adolesc Psychopharmacol 27: 383-388. [Crossref]

7. American Psychiatric Association. Diagnostic and Statistical Manual of Mental Disorders (2013) fifth ed., Washington DC.

8. Huang J, Manning BD (2009) A complex interplay between Akt, TSC2 and the two mTOR complexes. Biochem Soc Trans 37: 217-222. [Crossref]

9. Feliciano DM Lin TV, Hartman NW, Bartley CM, Kubera C et al. (2013) A circuitry and biochemical basis for tuberous sclerosis symptoms: from epilepsy to neurocognitive deficits. Int J Dev Neurosci 31: 667-678. [Crossref]

10. Magri L, Cambiaghi M, Cominelli M, Alfaro-Cervello C, Cursi M et al. (2011) Sustained activation of mTOR pathway in embryonic neural stem cells leads to development of tuberous sclerosis complex-associated lesions. Cell Stem Cell 9: 447462. [Crossref]

11. Cao J, Tyburczy ME, Moss J, Darling TN, Widlund HR et al. (2017) Tuberous sclerosis complex inactivation disrupts melanogenesis via mTORC1 activation. $J$ Clin Invest 127: 349-364. [Crossref]

12. Sato A, Kasai S, Kobayashi T, Takamatsu Y, Hino O et al. (2012) Rapamycin reverses impaired social interaction in mouse models of tuberous sclerosis complex. Nat Commun 3: 1292. [Crossref]

13. Kothare SV, Singh K, Hochman T, Chalifoux JR, Staley BA et al. (2014) Genotype phenotype in tuberous sclerosis complex: associations with clinical and radiologic manifestations. Epilepsia 55: 1020-1024. [Crossref]

14. Gipson TT1, Gerner G1, Wilson MA1, Blue ME1, Johnston MV1 (2013) Potential for treatment of severe autism in tuberous sclerosis complex. World J Clin Pediatr 2: 16-25. [Crossref]

15. Kumar P1, Raman T2, Swain MM1, Mishra R3, Pal A4 (2017) HyperglycemiaInduced Oxidative-Nitrosative Stress Induces Inflammation and Neurodegeneration via Augmented Tuberous Sclerosis Complex-2 (TSC-2) Activation in Neuronal Cells. Mol Neurobiol 54: 238-254. [Crossref]

16. Das A1, Durrant D, Koka S, Salloum FN, Xi L et al. (2014) Mammalian target of rapamycin (mTOR) inhibition with rapamycin improves cardiac function in type 2 diabetic mice: potential role of attenuated oxidative stress and altered contractile protein expression. J Biol Chem 289: 4145-4160. [Crossref] 
Yui K (2018) The role of antioxidant proteins in improvement of autism core symptoms in two patients with tuberous sclerosis treated with mTOR inhibitor everolimus

17. Nita M, Grzybowski A (2016) The Role of the reactive oxygen species and oxidative stress in the pathomechanism of the age-related ocular diseases and other pathologies of the anterior and posterior eye segments in adults. Oxid Med Cell Longev 2016: 3164734. [Crossref]

18. Rojo F, Domingo L, Sala M, Zazo S, Chamizo C, Menendez S et al. (2014) Gene expression profiling in true interval breast cancer reveals overactivation of the mTOR signaling pathway. Cancer Epidemiol Biomarkers Prev 23: 288-299. [Crossref]

19. Bayeva M, Khechaduri A, Puig S, Chang HC, Patial S et al. (2012) mTOR regulates cellular iron homeostasis through tristetraprolin. Cell Metab 16: 645-657. [Crossref]

20. Galvez T1, Teruel MN, Heo WD, Jones JT, Kim ML et al. (2007) siRNA screen of the human signaling proteome identifies the PtdIns $(3,4,5) \mathrm{P} 3$-mTOR signaling pathway as a primary regulator of transferrin uptake. Genome Biol 8: R142. [Crossref]

21. Gul Mert G, Herguner MO, Incecik F, Altunbasak S, Sahan D et al. (2017) Risk factors affecting prognosis in infantile spasm. Int J Neurosci 1: 7. [Crossref]

22. Staley BA, Vail, EA, Thiele EA (2011) Tuberous sclerosis complex: diagnostic challenges, presenting symptoms, and commonly missed signs. Pediatrics 127: e117125. [Crossref]

23. Kim SH, Thurm A, Shumway S, Lord C (2013) Multisite study of new autism diagnostic interview-revised (ADI-R) algorithms for toddlers and young preschoolers. J Autism Dev Disord 43: 1527-1538. [Crossref]

24. Hus V, Lord C (2013) Effects of child characteristics on the Autism Diagnostic, Interview-Revised: implications for use of scores as a measure of ASD severity. $J$ Autism Dev Disord 43: 371-381. [Crossref]

25. Kamp-Becker I1, Ghahreman M, Heinzel-Gutenbrunner M, Peters M, Remschmidt H et al. (2013) Evaluation of the revised algorithm of Autism Diagnostic Observation Schedule (ADOS) in the diagnostic investigation of high-functioning children and adolescents with autism spectrum disorders. Autism 17: 87-102. [Crossref]

26. Rynkiewicz A, Schuller B, Marchi E, Piana S, Camurri A, et al. (2016) An investigation of the 'female camouflage effect' in autism using a computerized ADOS-2 and a test of sex/gender differences. Mol Autism 7: 10. [Crossref]

27. Wechsler D (2003) Wechsler Intelligence Scale for Children-forth edition (WISC-IV). Psychological Corporation, San Antonio, TX.

28. Haysom L, Indig D, Moore E (2014) Intellectual disability in young people in custody in New South Wales, Australia - prevalence and markers. $J$ Intellect Disabil Res 58: 1004-1014.

29. Constantino JN, Gruber G (2005) The Social Responsiveness Scale (SRS). Western Pyschological Services, Los Angeles.

30. Barnard-Brak L1, Brewer A2, Chesnut S2, Richman D1, Schaeffer AM2 (2016) The sensitivity and specificity of the social communication questionnaire for autism spectrum with respect to age. Autism Res 9: 838-845. [Crossref]

31. Cheon KA1, Park JI1, Koh YJ2, Song J3, Hong HJ4, et al. (2016) The social responsiveness scale in relation to DSM IV and DSM5 ASD in Korean children. Autism Res 9: 970-980. [Crossref]

32. Rojahn J1, Aman MG, Matson JL, Mayville E (2003) The Aberrant Behavior Checklis and the Behavior Problems Inventory: convergent and divergent validity. Res Dev Disabil 24: 391-404. [Crossref]

33. Hollander E, Chaplin W, Soorya L, Wasserman S, Novotny S et al. (2009) Divalproex sodium vs. placebo for the treatment of irritability in children and adolescents with autism spectrum disorders. Neuropsychopharmacology 35: 990-998. [Crossref]

34. Singh K1, Connors SL2, Macklin EA3, Smith KD4, Fahey JW5 et al. (2014) Sulforaphane treatment of autism spectrum disorder (ASD). Proc Natl Acad Sci U S A 111: 15550-15555. [Crossref]

35. Johnson S, Hollis C, Hennessy E, Kochhar P, Wolke D et al. (2011) Screening for autism in preterm children: diagnostic utility of the Social Communication Questionnaire. Arch Dis Child 96: 73-77. [Crossref]

36. Grünwald V, Seidel C, Fenner M, Ganser A, Busch J et al. (2011) Treatment of everolimus-resistant metastatic renal cell carcinoma with VEGF-targeted therapies. $\mathrm{Br}$ J Cancer 105: 1635-1639. [Crossref]

37. Malinowska IA1, Lee N, Kumar V, Thiele EA, Franz DN, et al. (2013) Similar trends in serum VEGF-D levels and kidney angiomyolipoma responses with longer duration sirolimus treatment in adults with tuberous sclerosis. PLoS One 8: e56199. [Crossref]

38. Truillet C, Cunningham JT, Parker MFL, Huynh LT, Conn CS et al. (2016) Noninvasive measurement of mTORC1 signaling with $89 \mathrm{Zr}$-transferrin. Clin Cancer Res 23: 3045-3052. [Crossref]
39. Kim H, An S, Ro SH, Teixeira F, Park GJ et al. (2015) Janus-faced Sestrin2 controls ROS and mTOR signalling through two separate functional domains. Nat Commun 6 : 10025. [Crossref]

40. Majumder M1, Tutunea-Fatan E, Xin X, Rodriguez-Torres M, Torres-Garcia J, et al (2012) Co-expression of $\hat{\mathrm{I}} \pm 9 \hat{\mathrm{I}}^{2} 1$ integrin and VEGF-D confers lymphatic metastatic ability to a human breast cancer cell line MDA-MB-468LN. PLoS One 7: e35094. [Crossref]

41. Xu B, Wu Y, Shen L, Ye D, Jappe A (2011) Two-dose-level confirmatory study of the pharmacokinetics and tolerability of everolimus in Chinese patients with advanced solid tumors. J Hematol Oncol 4: 3. [Crossref]

42. Senra Varela A, Lopez Saez JJ, Quintela Senra D (1997) Serum ceruloplasmin as a diagnostic marker of cancer. Cancer Lett 121: 139-45. [Crossref]

43. Okado-Matsumoto A, Fridovich I (2001) Assay of superoxide dismutase: cautions relevant to the use of cytoch Irome c, a sulfonated tetrazolium, and cyanide. Anal Biochem 298: 337-342. [Crossref]

44. Pfeiffer CM, Cook JD, Mei Z, Cogswell ME, Looker AC et al. (2007) Evaluation of an automated soluble transferrin receptor (sTfR) assay on the Roche Hitachi analyzer and its comparison to two ELISA assays. Clin Chim Acta 38: 112-116. [Crossref]

45. Benifla M1, Merkin V2, Rosenthal G3, Shoshan Y3, Melamed I2 (2016) Supraciliary keyhole craniotomy for anterior frontal lesions in children. J Clin Neurosci 26: 37-41. [Crossref]

46. Amo C1, Saldaña C, Hidalgo MG, Maestú F, Fernández A et al. (2003) Magnetoencephalographic localization of peritumoral temporal epileptic focus previous surgical resection. Seizure 12: 19-22. [Crossref]

47. Kovarik JM1, Tedesco H, Pascual J, Civati G, Bizot MN, et al. (2004) Everolimus therapeutic concentration range defined from a prospective trial with reduced-exposure cyclosporine in de novo kidney transplantation. Ther Drug Monit 26: 499-505. [Crossref]

48. Page AC1, Cunningham NK1, Hooke GR2 (2016) Using daily monitoring of psychiatric symptoms to evaluate hospital length of stay. BJPsych Open 2: 341-345. [Crossref]

49. Hwang SK, Lee JH, Yang JE, Lim CS, Lee JA et al. (2016) Everolimus improves neuropsychiatric symptoms in a patient with tuberous sclerosis carrying a novel TSC2 mutation. Mol Brain 9: 56. [Crossref]

50. Webb NJ1, Bottomley MJ, Watson CJ, Brenchley PE (1998) Vascular endothelial growth factor (VEGF) is released from platelets during blood clotting: implications for measurement of circulating VEGF levels in clinical disease. Clin Sci (Lond) 94 395-404. [Crossref]

51. Young L, Lee HS, Inoue Y, Moss J, Singer LG, et al. (2013) Serum VEGF-D a concentration as a biomarker of lymphangioleiomyomatosis severity and treatment response: a prospective analysis of the Multicenter International Lymphangioleiomyomatosis Efficacy of Sirolimus (MILES) trial. Lancet Respir Med 1: 445-452. [Crossref]

52. Kotulska K1, Chmielewski D, Borkowska J, Jurkiewicz E, Kuczynski D et al. (2013) Long-term effect of everolimus on epilepsy and growth in children under 3 years of age treated for subependymal giant cell astrocytoma associated with tuberous sclerosis complex. Eur J Paediatr Neurol 17: 479-485. [Crossref]

53. Sheth RA, Feldman AS, Paul E, Thiele EA, Walker TG (2016) Angiographic and volumetric effects of mammalian target of rapamycin inhibitors on angiomyolipomas in tuberous sclerosis. World J Radiol 8: 308-315. [Crossref]

54. Franz DN, Belousova E, Sparagana S, Bebin EM, Frost MD et al. (2016) Long-Term Use of Everolimusin in patients with Tuberous Sclerosis Complex: Final Results from the EXIST-1 Study. PLoS One 11: e0158476. [Crossref]

55. Bissler JJ1, Kingswood JC2 (2016) Optimal treatment of tuberous sclerosis complex associated renal angiomyolipomata: a systematic review. Ther Adv Urol 8: 279-290. [Crossref]

56. Kweider N, Rath W, Huppertz B, Wruck CJ, Jumakuliev G et al. (2012) PP015. Differential expression of Nrf2 and VEGF in human placental beds from normal and pregnancies complicated with preeclampsia and IUGR. Pregnancy Hypertens 2: 248249. [Crossref]

57. Papiewska-Pajak I, Balcerczyk A, Stec-Martyna E, Koziolkiewicz W Boncela J (2017) Vascular endothelial growth factor-D modulates oxidant-antioxidant balance of human vascular endothelial cells. $J$ Cell Mol Med 21: 139-1149. [Crossref]

58. Dermit M1, Casado P1, Rajeeve V1, Wilkes EH1, Foxler DE2, et al. (2017) Oxidative stress downstream of mTORC1 but not AKT causes a proliferative defect in cancer cells resistant to PI3K inhibition. Oncogene 36: 2762-2774. [Crossref] 
Yui K (2018) The role of antioxidant proteins in improvement of autism core symptoms in two patients with tuberous sclerosis treated with mTOR inhibitor everolimus

59. Ramos D1, Mar D1, Ishida M1, Vargas R1, Gaite M1 et al. (2016) Mechanism of Copper Uptake from Blood Plasma Ceruloplasmin by Mammalian Cells. PLoS One 11: e0149516. [Crossref]

60. Aouffen M, Paquin J, De Grandpré E, Nadeau R, Mateescu MA (2001) Deglycosylated ceruloplasmin maintains its enzymatic, antioxidant, cardioprotective, and neuronoprotective properties. Biochem Cell Biol 79: 489- 497. [Crossref]

61. Lou JR1, Zhang XX, Zheng J, Ding WQ (2010) Transient metals enhance cytotoxicity of curcumin: potential involvement of the NF-kappaB and mTOR signaling pathways. Anticancer Res 30: 3249-3255. [Crossref]

62. Li X, Zou K, Gou J, Du Q, Li D, He X, Li Z (2015) Effect of baicalin-copper on the induction of apoptosis in human hepatoblastoma cancer HepG2 cells. Med Oncol 32: 72. [Crossref]
63. Truillet C1, Cunningham JT2, Parker MFL1, Huynh LT1, Conn CS2, et al. (2017) Noninvasive Measurement of mTORC1 Signaling with 89Zr-Transferrin. Clin Cancer Res 23: 3045-3052. [Crossref]

64. White KN, Conesa C, Sánchez L, Amini M, Farnaud S, et al. (2012) The transfer of iron between ceruloplasmin and transferrins. Biochim Biophys Acta 1820: 411- 416. [Crossref]

65. Glezer I1, Chernomoretz A, David S, Plante MM, Rivest S (2007) Genes involved in the balance between neuronal survival and death during inflammation. PLoS One 2: e310. [Crossref]

66. Agarwal A, SalehA RA, Bedaiwy MA (2003) Role of reactive oxygen species in the pathophysiology of human reproduction. Fertil Steril 79: 829-843. [Crossref]

Copyright: (2018 Yui K. This is an open-access article distributed under the terms of the Creative Commons Attribution License, which permits unrestricted use, distribution, and reproduction in any medium, provided the original author and source are credited. 